\title{
Changes in Metabolic Activity of Proteus mirabilis during Swarming
}

\author{
By JUDITH P. ARMITAGE \\ Department of Botany and Microbiology, University College London, Gower Street, \\ London WCIE 6BT, U.K.
}

(Received 27 October 1980; revised 28 January 1981)

\begin{abstract}
Proteus mirabilis in the long, swarming form had altered metabolic activity compared with bacteria in non-swarming phases on solid media. During swarming the rates of incorporation of precursors into DNA, RNA and protein, as measured in broth cultures immediately after harvesting from swarm plates, were lowered. The rates of uptake of these precursors into the bacteria were also lowered, and at the same time the rate of oxygen uptake was reduced to less than $20 \%$ of the normal rate, although intracellular ATP concentrations remained constant. The return of macromolecular synthesis and oxygen uptake to preswarming rates corresponded to the end of the active swarm period. The results indicate that in the multiflagellate swarmers of $P$. mirabilis metabolic activity was lowered to a level necessary to maintain flagella activity but not bacterial growth.
\end{abstract}

\section{INTRODUCTION}

When grown on suitable solid media Proteus mirabilis undergoes a cyclical morphology change. The short, sparsely flagellate, mononucleate rods at the edge of the colony become after a few hours, multinucleate, highly flagellate non-septate filaments up to $100 \mu \mathrm{m}$ long. These swarmers move through the surface moisture of the agar in groups or 'rafts' for distances of up to $1 \mathrm{~cm}$; they then slow down, stop and divide into short rods. The cycle is repeated until the agar surface is covered with rings of bacterial growth. This distinctive pattern of growth has been the subject of spasmodic research since it was first described in the nineteenth century. At different times positive chemotaxis, negative chemotaxis, nutritional effects, pressure of growth and slime production have all been put forward to explain the phenomenon (for reviews, see Smith, 1972; Williams \& Schwarzhoff, 1978).

Recent work has suggested that the cell envelope of swarmers is very different from that of non-swarmers (Armitage et al., 1979). The rapid increase in the number of flagella per unit area of cell wall before the onset of obvious swarming (Armitage \& Smith, 1978) results in a reorganization of the outer membrane and, consequently, increased sensitivity to hydrophobic antimicrobial agents.

In the present paper, evidence is presented to suggest that the metabolic activity of swarming cells is markedly different from that of non-swarming cells. Swarmers appear to be non-growing bacteria, and thus require a lower level of oxygen consumption to maintain the internal ATP concentration which appears to be used only to drive the rotation of the flagella.

\section{METHODS}

Growth and isolation of swarming and non-swarming Proteus mirabilis. After incubation at $30^{\circ} \mathrm{C}$, with shaking, exponential phase broth-grown (Oxoid no. 2) Proteus mirabilis (strain P11) was harvested by centrifugation and resuspended in the medium appropriate for the experiment. 
Swarmers were grown on $25 \times 25 \mathrm{~cm}$ culture plates containing $250 \mathrm{ml}$ nutrient broth (Oxoid no. 2) solidified with $1.75 \%(\mathrm{w} / \mathrm{v})$ Difco-Bacto agar. Twelve plates were each inoculated in eight positions. approximately $7 \mathrm{~cm}$ apart and incubated at $30^{\circ} \mathrm{C}$ for $16 \mathrm{~h}$. After this time the colonies were generally into their third swarm. The outer edges from the eight swarming colonies on two of the plates were isolated and combined into the appropriate medium. The procedure was repeated at hourly intervals for $6 \mathrm{~h}$. In this way the metabolic activity of the bacteria at the edge of the colonies was assayed over the time course of a swarm.

Immediately after the removal of the bacteria from the edge of the agar-grown colonies they were examined microscopically and their general appearance and activity was noted. The organisms were sized and counted in a Coulter counter (model ZF) and the turbidity was measured at $590 \mathrm{~nm}$. Together with the appearance of the colony this gave an accurate measure of the phase of the swarm cycle. The isolated suspensions were adjusted to the same turbidity $\left(A_{590}\right.$ approx. $\left.0 \cdot 60\right)$ for all experiments.

Measurement of incorporation of precursors into cellular macromolecules. Broth-grown bacteria were harvested and resuspended in fresh broth. When the culture reached exponential phase it was divided into three flasks: $\left[{ }^{14} \mathrm{C}\right.$ lphenylalanine (final concn $0.05 \mu \mathrm{Ci} \mathrm{ml}{ }^{-1}, 1.85 \mathrm{kBq} \mathrm{ml}{ }^{-1}$ ) was added to one flask: $\left[{ }^{3} \mathrm{H} \mid\right.$ thymidine (final concn $1 \mu \mathrm{Ci} \mathrm{ml}^{-1}, 37 \mathrm{kBq} \mathrm{ml}{ }^{-1}$ ) and $1.5 \mathrm{~mm}$ unlabelled uridine were added to the second; and $\left[{ }^{14} \mathrm{Cluracil}\right.$ (final concn $0.5 \mu \mathrm{Ci} \mathrm{m} l^{-1}, 18.5 \mathrm{kBq} \mathrm{ml}^{-1}$ ) and $35 \mu \mathrm{g}$ unlabelled uracil $\mathrm{ml}^{-1}$ were added to the third. (Radiochemicals were from Amersham.) Samples $(0.1 \mathrm{ml})$ were withdrawn from each flask at zero time and delivered on to $23 \mathrm{~mm}$ discs of Whatman $3 \mathrm{MM}$ paper; incorporation was stopped by the addition of ice-cold $5 \%$ (w/v) trichloroacetic acid (TCA), containing unlabelled precursor. Samples were taken every 5 min for 45 min. After $1 \mathrm{~h}$ in $5 \%$ TCA the discs were washed twice in ice-cold $5 \%$ TCA, once in ethanol/ether $(50: 50, \mathrm{v} / \mathrm{v})$ and finally in pure ether. After drying, the discs were added to $5 \mathrm{ml} 0.5 \%(\mathrm{w} / \mathrm{v}) 2$ 2-(4'-tert-butylphenyl)-5-(4"biphenylyl)-1,3,4-oxadiazole (butyl PBD)/toluene scintillation fluid and the amount of radioactivity was counted in a Tricarb scintillation counter.

The same procedure was followed for swarmers but the experiments were started immediately after their isolation into broth.

Measurement of the rate of uptake of phenylalanine into bacteria. Bacteria were resuspended in broth containing $100 \mu \mathrm{g}$ chloramphenicol $\mathrm{ml}^{-1}$ to inhibit protein synthesis. Samples $(0.1 \mathrm{ml})$ were taken every $30 \mathrm{~s}$ after the addition of ${ }^{14} \mathrm{C}$ lphenylalanine (final concn $0.05 \mathrm{mCi} \mathrm{ml}^{-1}, 1.85 \mathrm{MBq} \mathrm{ml}{ }^{-1}$ ). Bacteria were collected by vacuum filtration, washed with ice-cold buffer and the amount of radioactivity on the washed filter discs was counted.

Measurement of internal ATP concentration. The intracellular ATP present in a particular swarm phase was determined by precipitating the protein in pelleted samples of bacteria with $0.5 \mathrm{ml} 0.5 \mathrm{M}$-perchloric acid, and then measuring the ATP in the neutralized supernatant using the fluorimetric method of Estabrook \& Maitra (1962).

Measurement of the rate of oxygen uptake. The rate of oxygen uptake was measured using a Rank oxygen electrode. The bacterial suspension $\left(0.2 \mathrm{ml}, A_{\underline{590}} 5.0\right)$ was added immediately after isolation to $1.6 \mathrm{ml}$ $0.01 \mathrm{M}$-potassium phosphate buffer containing $0.1 \mathrm{mM}-\mathrm{EDTA}, \mathrm{pH} 7$, and the endogenous rate of oxygen uptake was calculated. Sodium succinate $(0.1 \mathrm{ml}$ of a $1 \mathrm{M}$ solution) was then added and the new rate of uptake was calculated. The results were checked by the addition of $20 \mu 30 \mathrm{~mm}-\mathrm{KCN}$.

\section{RESULTS}

The results presented here for each experiment come from one swarm cycle, although each experiment was repeated at least four and usually six times with similar results. Results of only one experiment (in duplicate) are presented rather than the average of all experiments because although the inoculation and isolation procedure were carried out in the same way for each assay it was impossible to guarantee that the cells were in the identical swarm phase at the same time each day. The experiments depended on starting the analysis as soon as possible after isolation of the bacteria from the agar surface. This made it impossible to use separation techniques to concentrate the different cell sizes. When active swarming was occurring it was fairly straightforward to remove the swarming zone with few short cells (about $80 \%$ may be more than four cell lengths), but in early preswarming stages it was impossible to isolate anything but a mixed population of swarmer, preswarmer and short bacteria.

Previous unpublished observations with swarmers isolated into nutrient broth have suggested that the viability of long cells in liquid medium, replated at various time intervals on to solid media, is high; colony production closely paralleled cell number over $2 \mathrm{~h}$. 


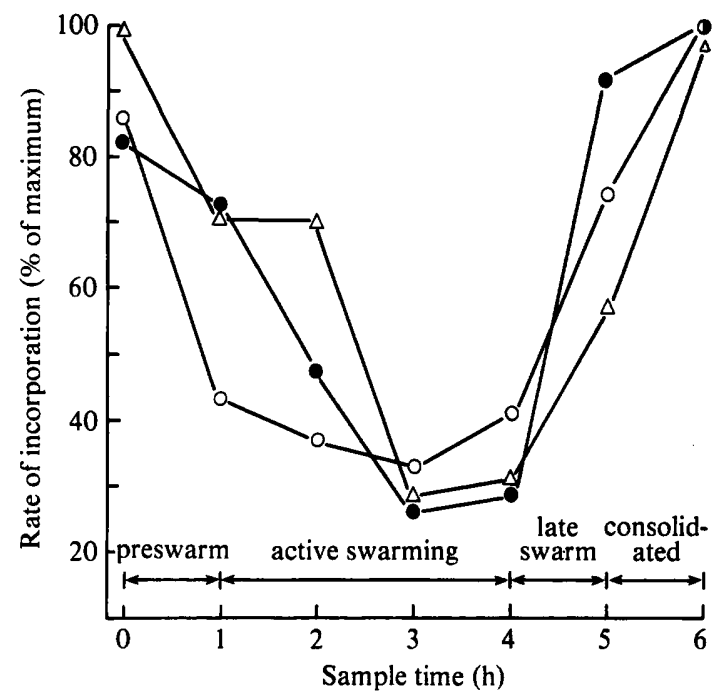

Fig. 1. Incorporation of $\left[{ }^{14} \mathrm{C}\right.$ phenylalanine (O), $\left[{ }^{14} \mathrm{C}\right]$ uracil $(O)$ and $\left[{ }^{3} \mathrm{H}\right]$ thymidine $(\triangle)$ into the TCAprecipitable fraction of swarming bacteria of $\boldsymbol{P}$. mirabilis as a percentage of the incorporation into exponential phase broth-grown bacteria at an equivalent $A_{\mathbf{9 9 0}}$. At hourly intervals samples from identical plates were removed into broth, the labelled precursor was added immediately and incorporation was followed as described in Methods.
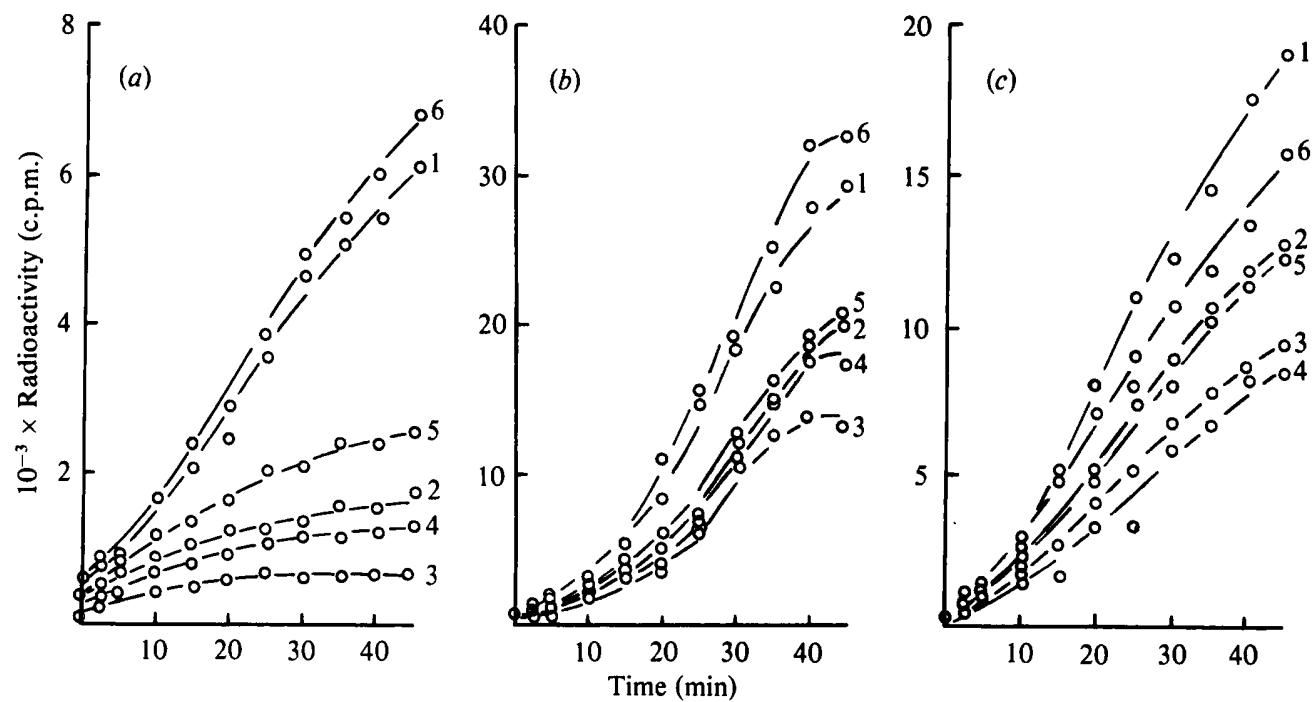

Fig. 2. Accumulation of $\left[{ }^{14} \mathrm{C}\right.$ uracil $(a),\left[{ }^{14} \mathrm{C}\right]$ phenylalanine $(b)$ and $\left[{ }^{3} \mathrm{H}\right]$ thymidine $(c)$ in nucleic acid and protein of swarmers of $P$. mirabilis isolated into broth at different times during the swarm cycle; the time (h) of sampling is indicated by the numbers on the curves.

\section{Incorporation of precursors into macromolecules}

Figures 1 and 2 show the incorporation of $\left[{ }^{14} \mathrm{C}\right]$ uracil, $\left[{ }^{3} \mathrm{H}\right]$ thymidine and $\left[{ }^{14} \mathrm{C}\right]$ phenylalanine into TCA-precipitable fractions of agar-grown $P$. mirabilis at hourly intervals during the swarm cycle related to the rates of incorporation in a similar fraction in exponentially growing bacteria in liquid broth culture. Before visible swarmer development, agar-grown cells showed rates of incorporation of macrornolecular precursors similar to exponential 


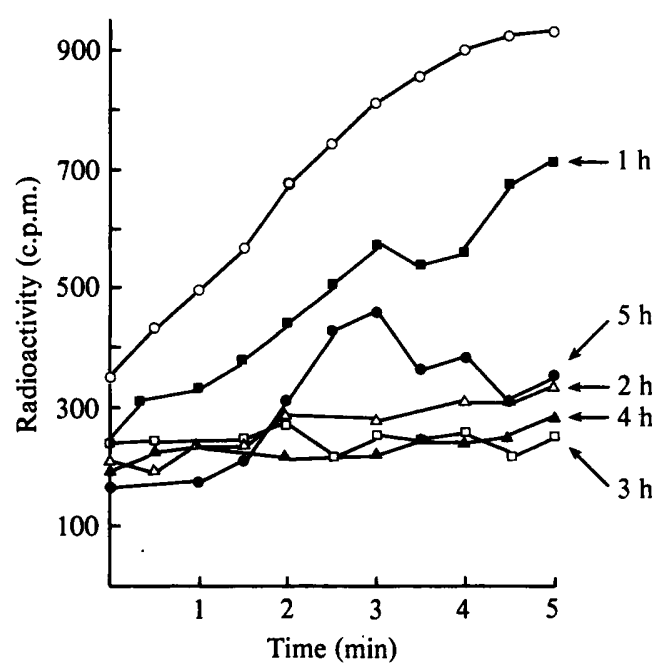

Fig. 3 Uptake of $\left[{ }^{14} \mathrm{C}\right.$ ]phenylalanine into swarmers during the swarm cycle. The samples were isolated into broth at intervals through the swarm cycle as described in Methods; the time of sampling is indicated on the curves. The uptake into exponential phase broth-grown cells is also shown (O).

Table 1. Rate of oxygen uptake by non-swarming and swarming cells of $P$. mirabilis and internal ATP concentrations in analogous samples

The rate of oxygen uptake and internal concentration of ATP were measured immediately after isolation into broth, as described in Methods.

\begin{tabular}{|c|c|c|c|}
\hline \multirow[b]{2}{*}{ Growth condition } & \multicolumn{2}{|c|}{ 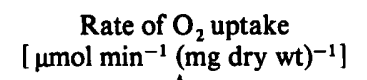 } & \multirow{2}{*}{$\begin{array}{c}\text { ATP concentration } \\
{\left[\mu \mathrm{mol} \mathrm{min}^{-1}(\mathrm{mg} \text { dry } \mathrm{wt})^{-1}\right]}\end{array}$} \\
\hline & Endogenous & With succinate & \\
\hline $\begin{array}{l}\text { Broth-grown } \\
\text { Swarm inhibiting }\end{array}$ & 4.6 & 10.4 & 1.7 \\
\hline agar-grown & 5.0 & 7.8 & 2.0 \\
\hline Early swarm (0) & $4 \cdot 8$ & $15 \cdot 6$ & $2 \cdot 6$ \\
\hline Active swarm (1 h) & 2.0 & $3 \cdot 8$ & 1.8 \\
\hline Active swarm (2 h) & 0.8 & $1 \cdot 4$ & 1.9 \\
\hline Active swarm (3 h) & 0.8 & 1.4 & $2 \cdot 0$ \\
\hline Active late swarm (4 h) & $2 \cdot 0$ & $4 \cdot 2$ & $2 \cdot 6$ \\
\hline Consolidated $(5 \mathrm{~h})$ & $4 \cdot 2$ & $12 \cdot 0$ & $3 \cdot 0$ \\
\hline
\end{tabular}

phase broth-grown cells. Microscopic and sizing results suggested that this rate of incorporation continued until swarmer cells started to form. With the appearance of swarmers the rate of incorporation at comparable cell densities was lowered until, when active swarming was occurring across the agar plate, the rate of incorporation was $50 \%$ or less of the preswarming rate. It was difficult to state the exact extent of the reduction as some short bacteria were always carried with the rafts of swarmers, and early swarmer cells which are long but not swarming were very difficult to isolate without a large number of short cells. The intermediate rates of incorporation seen with early swarmers may reflect a mixture of short cells in which incorporation was at a maximum and long cells with a minimum rate of incorporation, rather than an intermediate rate of incorporation in all the cells. When the rafts of swarmers slowed and stopped at the end of the swarm cycle and cell division recommenced the rates of incorporation returned to the preswarm levels.

Figure 3 shows the rates of uptake of $\left[{ }^{14} \mathrm{C}\right]$ phenylalanine into short and long cells. The results show that the decrease in the rate of incorporation of phenylalanine into swarming 
bacteria was at least partly a reflection of a reduction in the rate of uptake of the precursors. The rate of uptake increased at approximately the same time in the swarm cycle as the rate of incorporation of phenylalanine into the TCA-precipitable fraction increased.

\section{Internal concentration of ATP during swarming}

There was no significant change in the internal concentration of ATP during swarming (Table 1). Fluctuations in internal ATP concentrations do not seem therefore to control swarming activity.

\section{Rate of oxygen consumption during swarming}

Although the ATP concentration remained constant, and similar to that in broth-grown aerobic cells, the rate of oxygen consumption in swarmers, measured immediately after removal from plates, fell to a low level during active swarming (Table 1). In contrast, during non-swarming growth on agar the rate of oxygen uptake was similar to that of broth-grown cells and showed a similar increase in rate on the addition of succinate. The rate of oxygen uptake by swarmer cells isolated into nutrient broth increased after about $1 \mathrm{~h}$ shaking and eventually returned to normal as the cell number increased and cell size decreased (results not shown).

\section{DISCUSSION}

The results presented here suggest that actively swarming $P$. mirabilis may have altered metabolic activity compared with non-swarming bacteria. Because all the bacteria at the edge of the colony do not appear to initiate filamentation at the same time, early and preswarming isolations result in a mixture ranging from very long $(100 \mu \mathrm{m})$ bacteria to short bacteria. The results suggest that as the proportion of very long swarmers in the isolated broth suspensions increased, the rate of incorporation of macromolecular precursors and rate of oxygen consumption decreased. At the end of a swarm phase, when the swarmers were starting to divide into short bacteria (consolidating), the rates of incorporation of precursors and oxygen consumption increased. Although technical problems make it difficult to isolate only swarmer cells, the results suggest that when swarmer cells reach a certain extent of flagellation and length and start swarming they may be metabolically very different from the short bacteria. Plating results and microscopic observation suggest that swarmer cells isolated into broth remain viable; therefore these results are probably not due to increased cell death on isolation of swarmers.

Isolated, washed swarmers re-inoculated on to nutrient-free medium travelled approximately the same distance as they would have done on nutrient media (Williams et al., 1976), which suggests an internal control to swarming, independent of the external nutrient supply. Douglas (1979) showed that early swarmers were very motile but became progressively slower as they crossed the agar surface, eventually stopping before consolidation. As the speed of flagella rotation is related to the proton motive force across the membrane, this result suggests that the proton gradient, at least as related to the flagella motor, was lowered progressively during active swarming.

It has been suggested that $P$. mirabilis swarmers may produce an Alcian Blue-stainable storage material not seen in non-swarming bacteria (unpublished results, cited by Williams \& Schwarzhoff, 1979). Work in this laboratory has not been conclusive in showing any storage material, but it seems possible that the production of a storage material may be involved. Swarming bacteria could use this internal limiting energy source to maintain their ATP concentrations and proton potentials and thus drive their flagella. When this energy source has finally been metabolized the proton gradient would fall and flagella rotation would slow. Simultaneously, the as yet unknown inhibitor of cell division would be removed and the long, multinucleate bacteria would divide into short, sparsely flagellate non-swarmers. It is probable 
that the decreased rate of oxygen consumption seen in active swarmers is a reflection of the lower energy requirements of bacteria with repressed synthetic activity, the amount of energy required to maintain a membrane potential sufficient to drive flagella rotation presumably being a fraction of that needed for growth.

These results leave unresolved the problem of the outward movement of the bacterial colony and the formation of the swarming pattern. If swarming were only the response to the use of an internal metabolite and the formation of very motile bacteria able to overcome surface tension, the result would be a thin spreading film of bacteria away from the control colony. However, Proteus creates, initially, an almost bacteria-free zone between the travelling band and the original colony. It has been observed (Macnab, 1978) that Salmonella suppressed tumbling motility when energy was at a reduced steady state level and only swam smoothly until either a new nutrient source was reached or all internal energy sources were depleted. It is possible that the repression of metabolic activity in swarmers causes a response similar to starvation. If swarmers were smooth swimming there would be a tendency for them to be deflected away from the barrier of the main colony and thus spread outwards. Microscopic observation of $P$. mirabilis swarmers suggests that they change direction very rarely, moving rapidly against and away from other groups of swarmers.

The swarming of $P$. mirabilis is the result of a complex, interconnected series of events leading to the formation of a swarmer which appears in many ways to be unlike the short parent bacterium. Whether the cycle has any role in the normal environment of the organism or is a response to growth in a physically alien environment has yet to be elucidated.

I would like to thank P. Keighley for technical assistance and Dr D. G. Smith for critical reading of the manuscript. The work was supported by a grant from the Science Research Council.

\section{REFERENCES}

ARmitage, J. P. \& Smith, D. G. (1978). Flagella development during swarmer differentiation in Proteus mirabilis. FEMS Microbiology Letters 4, 163-165.

Armitage, J. P., Smith, D. G. \& Rowbury, R. J. (1979). Alterations in the cell envelope composition of Proteus mirabilis during the development of swarmer cells. Biochimica et biophysica acta 584, 389-397.

Douglas, C. W. I. (1979). Measurement of Proteus cell motility during swarming. Journal of Medical Microbiology 12, 195-199.

EstabrooK, R. W. \& MAItra, P. K. (1962). A fluorimetric method for the quantitative microanalysis of adenine and pyridine nucleotides. Analytical Biochemistry 3, 369-382.
MACNAB, R. M. (1978). Bacterial motility and chemotaxis: the molecular biology of a behavioural response. CRC Critical Reviews in Biochemistry 5, 291-341.

Smith, D. G. (1972). The Proteus swarming phenomenon. Science Progress 60, 487-506.

Williams, F. D. \& Schwarzhoff, R. H. (1978). Nature of the swarming phenomenon in Proteus. Annual Review of Microbiology 32, 101-122.

Williams, F. D., Anderson, D. M., Hoffman, P. S., SCHWARZHOFF, R. H. \& LEONARD, S. (1976). Evidence against the involvement of chemotaxis in swarming in Proteus mirabilis. Journal of Bacteriology 127, 237-248. 